http://dx.doi.org/10.32929/2446-8355.2019v28n3p343-353

\title{
PERÍODOS DE SECAGEM NA QUALIDADE FISIOLÓGICA DE SEMENTES DE CACAU
}

\author{
Kennia Karolline Gonçalves Pereira ${ }^{1}$, Andréia Márcia Santos de Souza David ${ }^{2}$, Josiane \\ Cantuária Figueiredo ${ }^{1}$, Aparecida Rodrigues de Jesus Carvalho ${ }^{3}$, Victor Martins Maia ${ }^{2}$, \\ Danúbia Aparecida Costa Nobre ${ }^{4 *}$
}

\footnotetext{
${ }^{1}$ Mestrando, Produção Vegetal no Semiárido, Universidade Estadual de Montes Claros, Janaúba-MG. ${ }^{2}$ Docente, Produção Vegetal no Semiárido, Universidade Estadual de Montes Claros, Janaúba-MG. ${ }^{3}$ Doutorando, Produção Vegetal no Semiárido, Universidade Estadual de Montes Claros, Janaúba-MG. ${ }^{4}$ Pós-doutorando, Produção Vegetal no Semiárido, Universidade Estadual de Montes Claros, Janaúba-MG. *Email do autor correspondente: danubia_nobre@yahoo.com.br
}

Recebido: 22/05/2019; Aceito: 03/10/2019

RESUMO: As sementes de cacau recém-colhidas apresentam elevado teor de água o que impede o armazenamento, devido à rápida perda da viabilidade e vigor. Diante do exposto, objetivou-se no presente trabalho avaliar a influência de diferentes períodos de secagem na qualidade fisiológica de sementes de cacau. $\mathrm{O}$ delineamento experimental utilizado foi o inteiramente casualizado com os tratamentos constituídos de quatro períodos de secagem das sementes $(0,24,48$ e 72 horas) com quatro repetições. As sementes foram extraídas dos frutos manualmente e com auxílio de uma peneira foram lavadas em água corrente até a completa remoção da polpa. Após o despolpamento, as sementes foram postas sobre papel toalha e submetidas à secagem em condições de laboratório $\left(26{ }^{\circ} \mathrm{C}\right)$, de acordo os tratamentos descritos anteriormente. Avaliou-se o teor de água, germinação, tempo médio de germinação, emergência de plântulas, índice de velocidade de emergência e comprimento de plântulas. Conclui-se que a secagem afetou as sementes de cacau, o que confirma sua sensibilidade à dessecação, com efeitos fisiológicos prejudiciais, em especial, períodos prolongados. As sementes de cacau apresentam comportamento recalcitrante, comprometendo a viabilidade e o vigor à medida que o seu teor de água é reduzido. A secagem até o período de 24 horas mantém alta viabilidade das sementes.

Palavras-chave: Theobroma cacao. Recalcitrantes. Teor de água. Viabilidade.

\section{DRYING TIMES IN THE PHYSIOLOGICAL QUALITY OF COCOA BEANS}

ABSTRACT / RESUMO: Freshly harvested cocoa beans have a high water content which prevents storage due to the rapid loss of viability and vigor. In view of the above, the objective of this study was to evaluate the influence of different drying periods on the physiological quality of cocoa beans. The experimental design was completely randomized with treatments consisting of four periods of drying the seeds (0, 24, 48 and 72 hours) with four replicates. The seeds were extracted from the fruits manually and with a sieve were washed in running water until the pulp was completely removed. After the pulping, the seeds were placed on paper towels and dried under laboratory conditions $\left(26^{\circ} \mathrm{C}\right)$, according to the 
treatments described previously. The water content, germination, mean germination time, seedling emergence, emergence velocity index and seedling length were evaluated. It is concluded the drying affected the cocoa seeds, confirming its sensitivity to desiccation, with harmful physiological effects, especially during prolonged periods. Cocoa seeds have a recalcitrant behavior, compromising viability and vigor as their water content is reduced. Drying up to the 24 hour period maintains high seed viability.

Key words: Theobroma cacao. Recalcitrants. Water content. Viability.

\section{INTRODUÇÃO}

A propagação do cacaueiro (Theobroma cacao) se dá por sementes (seminal/sexuada) e de forma vegetativa (assexuada), sendo que o primeiro método possui como vantagem melhor manejo de poda, e o segundo, maior homogeneidade e menor ciclo de vida (SODRÉ, 2013). A propagação do porta-enxerto, predominantemente, de via seminal, justifica a necessidade de observação da viabilidade das sementes de cacau utilizadas como propágulo (VENIAL et al., 2017). Portanto, o sucesso de ambas as propagações, dependem inicialmente da germinação e vigor das sementes.

No entanto, as sementes de cacau consideradas recalcitrantes, não podem ser desidratadas abaixo de um determinado grau de umidade, sem que ocorram danos fisiológicos. Como a tolerância à dessecação está diretamente relacionada ao ambiente em que as sementes se desenvolvem, com alta umidade relativa, praticamente não perdem água durante a maturação, portanto, não há formação de mecanismos de proteção e as sementes podem sofrer injurias quando submetidas à secagem (NASCIMENTO et al., 2007).

A vida útil das sementes recalcitrantes maduras é curta, entre perceber a oportunidade de germinação até a desidratação, pode haver rápida perda de viabilidade. Esta limitação fisiológica está intimamente relacionada com a especificidade ecológica de habitats arbóreos recalcitrantes (OBROUCHEVA et al., 2016).

A identificação do período de secagem adequado constitui como instrumento importante para melhor conservação das sementes em relação ao armazenamento e a sua propagação. Nesse sentido, qualquer procedimento destinado ao uso das sementes de cacau a ser desenvolvido deve, entre outros aspectos, evitar a perda de água das sementes e a proliferação de microrganismos. Como alternativas, há a possibilidade de se recorrer à desidratação parcial das sementes.

Diante do exposto, objetivou-se no presente trabalho avaliar a influência de diferentes períodos de secagem na qualidade fisiológica de sementes de cacau.

\section{MATERIAL E MÉTODOS}

O ensaio foi realizado no Laboratório de Análise de Sementes do Departamento de Ciências Agrárias, em Janaúba - MG, na Universidade Estadual de Montes Claros (Unimontes). Foram utilizadas sementes de cacau oriundas de frutos fisiologicamente 
maduros (pericarpo amarelado) da variedade CEPEC 2002, colhidos aleatoriamente em uma população de plantas em plena produção na fazenda Experimental da Unimontes, em novembro de 2017. A região apresenta clima tropical com inverno seco, do tipo "AW" conforme a classificação de Koppen, a média anual para temperatura, precipitação e umidade relativa do ar, é de $25^{\circ} \mathrm{C}, 900 \mathrm{~mm}$ e $65 \%$, respectivamente (FIGUEIREDO et al., 2017).

As sementes foram extraídas de forma manual dos frutos recém colhidos, e despolpadas com auxílio de uma peneira, em seguida, lavadas em água corrente. Após, as sementes foram mantidas sobre papel toalha para secagem em condições de laboratório $\left(26 \pm 3{ }^{\circ} \mathrm{C}\right.$ e $65 \%$ de UR). A seguir, as sementes foram avaliadas quanto ao teor de água, a germinação e o vigor, no período de 0 hora, denominado testemunha sem secagem, os demais períodos de secagem (24, 48 e 72 horas) foram determinados e avaliados na sequência de cada tempo, em delineamento experimental inteiramente casualizado com quatro repetições

Teor de água - foi determinado conforme metodologia prescrita nas Regras para Análise de Sementes (BRASIL, 2009) utilizando o método de estufa a $105 \pm 3{ }^{\circ} \mathrm{C}$, durante 24 horas, com quatro repetições de 20 sementes, sendo os resultados expressos em porcentagem.

Germinação - utilizou-se quatro repetições de 25 sementes que foram semeadas em caixas plásticas, contendo como substrato areia lavada e esterilizada, a uma profundidade de $2,0 \mathrm{~cm}$. O substrato foi umedecido com quantidade de água equivalente a $60 \%$ da capacidade de retenção, onde foram feitas observações visuais e a reposição hídrica realizada com irrigações leves diárias. As caixas foram mantidas em germinador tipo Mangelsdorf (Prolab ${ }^{\circledR}$ ) previamente regulado à temperatura de $30^{\circ} \mathrm{C}$ constantes. As avaliações foram realizadas no vigésimo sétimo dia após a semeadura, e os resultados foram expressos em percentagem de plântulas normais (BRASIL, 2009).

Tempo médio de germinação - foi conduzido em conjunto com o teste de germinação, calculado a partir das sementes germinadas diariamente até o vigésimo sétimo dia após a semeadura, de acordo com a fórmula citada por Lima et al. (2006), sendo o resultado expresso em dias após a semeadura.

Emergência de plântulas - conduzido em condições ambientais de laboratório (26 \pm 3 ${ }^{\circ} \mathrm{C}$ ), a semeadura foi feita em caixas plásticas, contendo 25 sementes por repetição, em substrato areia lavada e esterilizada, umedecida com quantidade de água equivalente a $60 \%$ da capacidade de retenção, cuja umidade foi mantida por meio de regas diárias (BRASIL, 2009). As avaliações foram realizadas diariamente, desde a semeadura até a estabilização e uniformização das plântulas, a qual ocorreu no vigésimo sétimo dia após a semeadura.

Índice de velocidade de emergência (IVE) - realizado em conjunto com o teste de emergência de plântulas, anotando diariamente o número de plântulas normais emergidas até a estabilização da emergência. Ao final do teste, com os dados diários do número de sementes emergidas, foi calculado o índice de velocidade de emergência, empregando-se a fórmula proposta por Maguire (1962).

Comprimento de plântulas - ao final do teste de emergência foi determinado, com o auxílio de uma régua graduada, o comprimento das plântulas normais (inserção dos 
cotilédones até a raiz) de cada repetição, sendo os resultados expressos em cm plântula ${ }^{-1}$, adaptado de Nakagawa (1994).

Os dados coletados foram analisados quanto à homogeneidade de variância e a normalidade, em seguida, submetidos à análise de variância e posterior análise de regressão pelo teste "F" à 5\%; e as estimativas dos parâmetros da regressão, foram avaliados pelo teste “t” à 5\% (FIGUEIREDO et al., 2017).

\section{RESULTADOS E DISCUSSÃO}

Os períodos de secagem das sementes influenciaram significativamente todas as variáveis estudadas. Os dados referentes aos teores de água das sementes se ajustaram a um modelo de regressão de comportamento quadrático $(\mathrm{P}<0,05)$, com redução nos valores proporcionais aos períodos de secagem das sementes (Figura 1). No período inicial de avaliação (0 hora), as sementes apresentaram elevado teor de água $(69,79 \%)$, sendo que à medida que aumentou os períodos de secagem, houve reduções nos valores, atingindo ao longo das 72 horas, 21,08\% de umidade (Figura 1). Em nenhum dos períodos avaliados as sementes perderam completamente a sua viabilidade, não sendo possível fazer inferência sobre o teor de água letal.

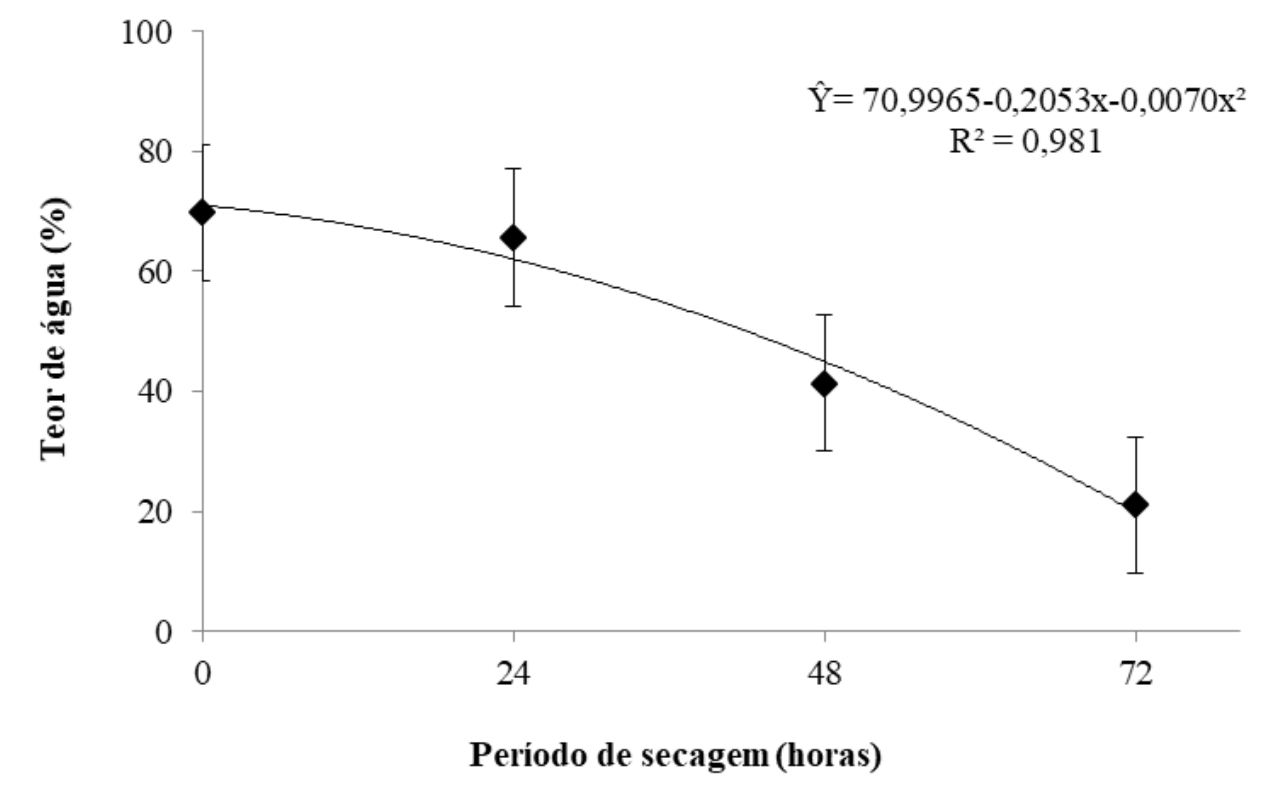

Figura 1. Teor de água $(\%)$ de sementes de cacau submetidas a diferentes períodos de secagem. Water content of cocoa beans submitted to different drying periods.

No período inicial de avaliações, as sementes se encontravam com alto teor de água em 69,79\%. Segundo Carvalho et al. (2006) é uma característica de sementes recalcitrantes, pois, ao contrário de sementes ortodoxas, as recalcitrantes não passam por uma dessecação acentuada durante a maturação e/ou antecedendo a dispersão. Normalmente essas sementes mantêm o teor de água acima dos 40\%, o que as tornam intolerantes a esse processo, dificultando a conservação. Assim, para essas sementes não é observada a chamada Fase 1 da embebição, caracterizada por rápida absorção de água, durante a fase inicial do processo de germinação (NAZÁRIO et al., 2008). 
Esse é o principal obstáculo enfrentado pelas commodities de cacau exportadas, a viabilidade das sementes, por serem recalcitrantes (TOYYIB et al., 2017), cuja secagem pode causar alterações que favoreçam a sua deterioração, há redução brusca nos teores de água com o tempo de secagem ou armazenamento, como observado em sementes de açaí (Euterpe oleracea Mart.), onde verificaram reduções nos teores de água de 43,4 para 11,9\% após 480 horas de secagem simulada (NASCIMENTO et al., 2007).

A germinação das sementes de cacau (Figura 2) foi influenciada pelos períodos de secagem, apresentando um comportamento linear. Nota-se que no período inicial de avaliação (0 hora) quando o teor de água das sementes era de 69,79\%, a germinação foi máxima $(100 \%)$.

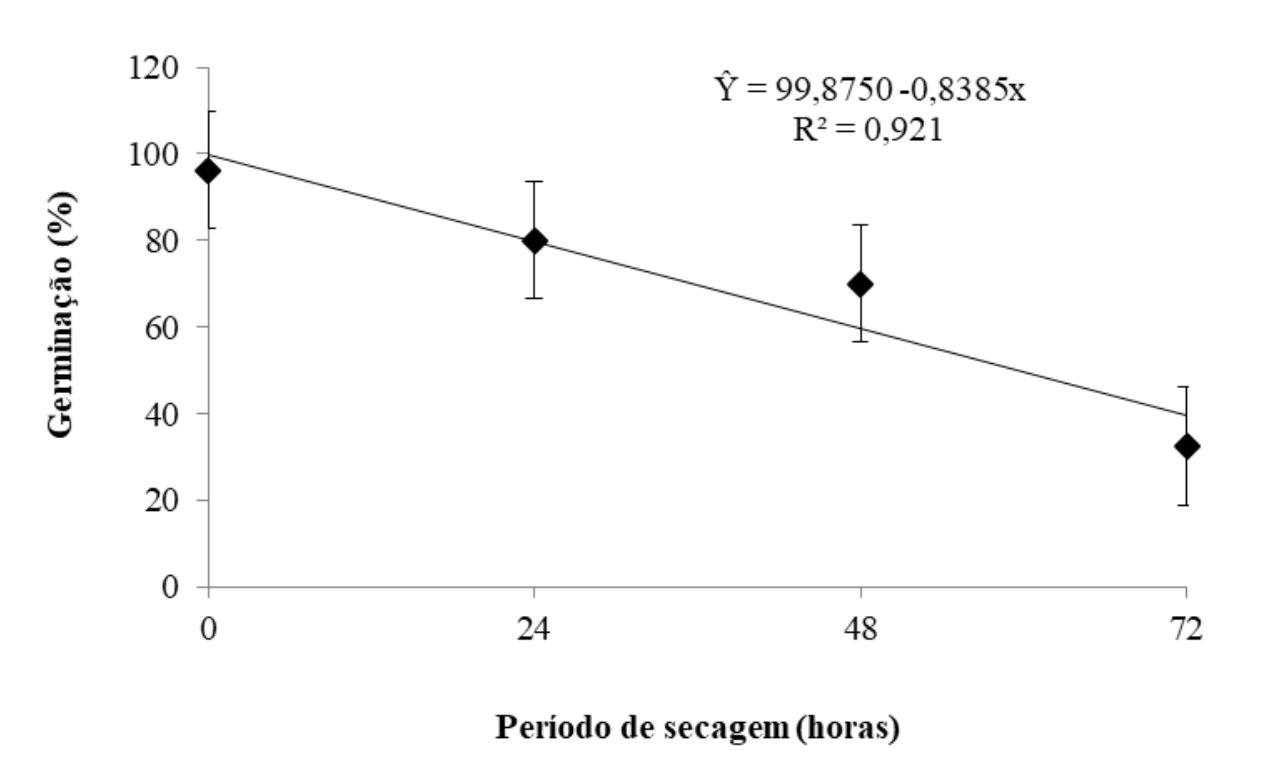

Figura 2. Germinação (\%) de sementes de cacau submetidas a diferentes períodos de secagem. Germination of cacao seeds submitted to different drying periods.

No entanto, a partir do período inicial houve decréscimo na germinação em $60 \%$ até as 72 horas de secagem, a qual apresentou $40 \%$ de germinação no período em que as sementes apresentavam 21,08\% de umidade (Figura 2). Esse decréscimo na germinação pode ser explicado em decorrência da redução do teor de água, pois, de acordo Nautiyal e Purohit (1985) a perda de água em sementes recalcitrantes desencadeia processo de deterioração, como a desnaturação de proteínas, alterações na atividade das enzimas peroxidases e danos no sistema de membranas, acarretando perda da viabilidade dessas sementes.

O tempo médio de germinação (TMG) apresentou comportamento linear crescente, com incrementos nos valores proporcionais ao aumento do período de secagem das sementes (Figura 3). Quanto menor o teor de água das sementes, maior foi o tempo médio de germinação, aumentando de 9 dias nas sementes que não passaram pela secagem (período inicial de avaliação), para 13 dias quando as sementes foram submetidas a 72 horas de secagem, mostrando que com a redução no teor de água as sementes requereram mais tempo para a germinação. 


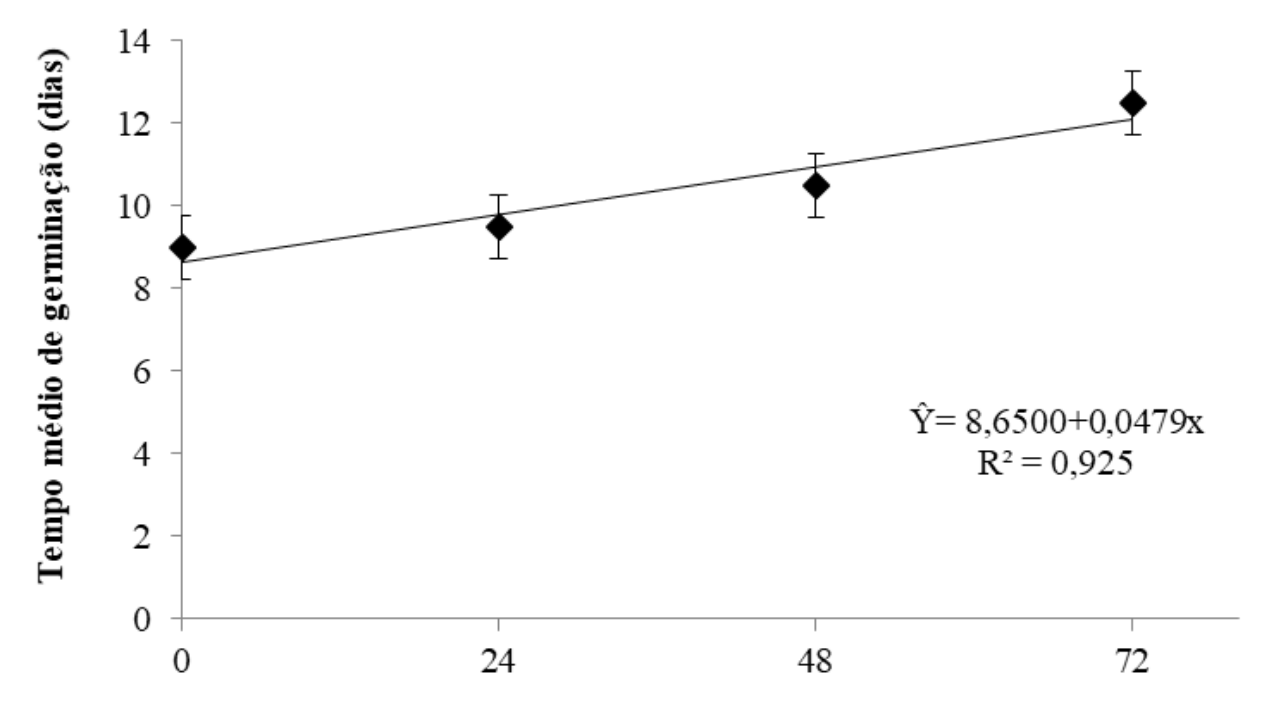

Período de secagem (horas)

Figura 3. Tempo médio de germinação de sementes de cacau submetidas a diferentes períodos de secagem. Average germination time of cocoa beans submitted to different drying periods.

Desta forma, confirma-se mais uma vez que as sementes de cacau quando se desliga fisiologicamente da planta mãe, possui elevado teor de água, sendo sensíveis a secagem, o que é uma característica típica de sementes recalcitrantes (CHIN et al., 1989), isso revela que com a redução do teor de água nas sementes, essas requereram maior tempo para a germinação.

Os resultados do presente estudo corroboram com os encontrados por Pirola et al. (2018), em sementes de cerejeira-da-mata (Eugenia involucrata DC), guabijuzeiro (Myrcianthes pungens (Berg) Legrand), sete capoteiro (Campomanesia guazumifolia (Cambess.) O.Berg), pitangueira (Eugenia uniflora L.), jabuticabeira híbrida (Plinia cauliflora Mart.) e jabuticabeira de cabinho (Plinia trunciflora O.Berg), onde o TMG nos menores períodos de secagem foi reduzido em relação aos maiores períodos.

A emergência de plântulas (Figura 4) foi influenciada pelos períodos de secagem das sementes, apresentando comportamento quadrático. No período inicial de avaliação, quando o teor de água das sementes era de 69,79\%, a porcentagem de emergência foi de 93,75\%. Já no período de 24 horas de secagem das sementes, o teor de água diminuiu para $65,65 \%$, e a emergência de plântulas reduziu cerca de 7,5\%, alcançando 86,25\% de plântulas emergidas. 


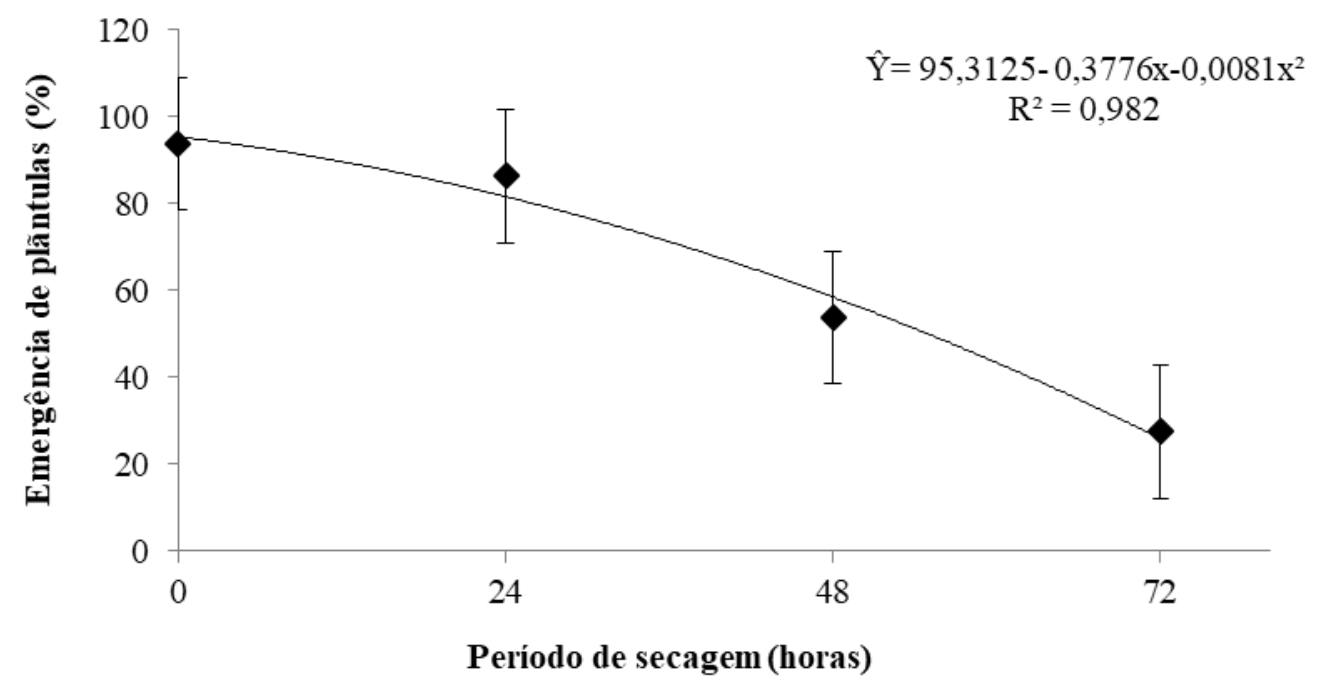

Figura 4. Emergência de plântulas (\%) oriundas de sementes de cacau submetidas a diferentes períodos de secagem. Emergence of seedlings from cocoa beans submitted to different drying periods.

Posteriormente, após 24 horas de secagem a emergência de plântulas continuou decrescendo progressivamente, ao mesmo tempo em que o teor de água continuava reduzindo, tendo alcançado emergência de plântulas de $27,5 \%$, no período de 72 horas de secagem das sementes, com teor de água de 21,08\% (Figura 4). Houve uma diferença percentual de $70,67 \%$ em relação a emergência inicial e final.

A água é essencial para a integridade de estruturas intracelulares, portanto o metabolismo desequilibrado e os danos provocados devido à desidratação são as principais causas da perda de viabilidade das sementes durante a secagem (BERJAK; PAMMENTER, 2003). Quando as sementes recalcitrantes são desidratadas logo após a colheita, ocorre uma redução gradual da viabilidade com o dessecamento, passando por um ponto crítico até atingir o teor de água chamado letal (NAZÁRIO et al., 2008).

O vigor das sementes avaliado pelo índice de velocidade de emergência (IVE), expressa que as sementes não submetidas a secagem (tempo 0) obtiveram o maior IVE, com valores de 2,07 (Figura 5). Maiores IVE indicam que as sementes germinaram mais rapidamente e de maneira uniforme, sendo, portanto, mais vigorosas. Contudo, nota-se que a medida que se prolongou a secagem das sementes ocorreu reduções de 43,4\% nos valores de IVE, atingindo índices de 1,17 no período de secagem de 72 horas.

Oliveira et al. (2011) trabalhando com sementes de jenipapo (Genipa americana L.), em dois ambientes (telado e laboratório) e diferentes tempos de secagem; e Cardoso et al. (2015) com sementes de pitomba (Talisia esculenta), verificaram que ocorreu queda progressiva no IVE com aumento do período de secagem das sementes. 


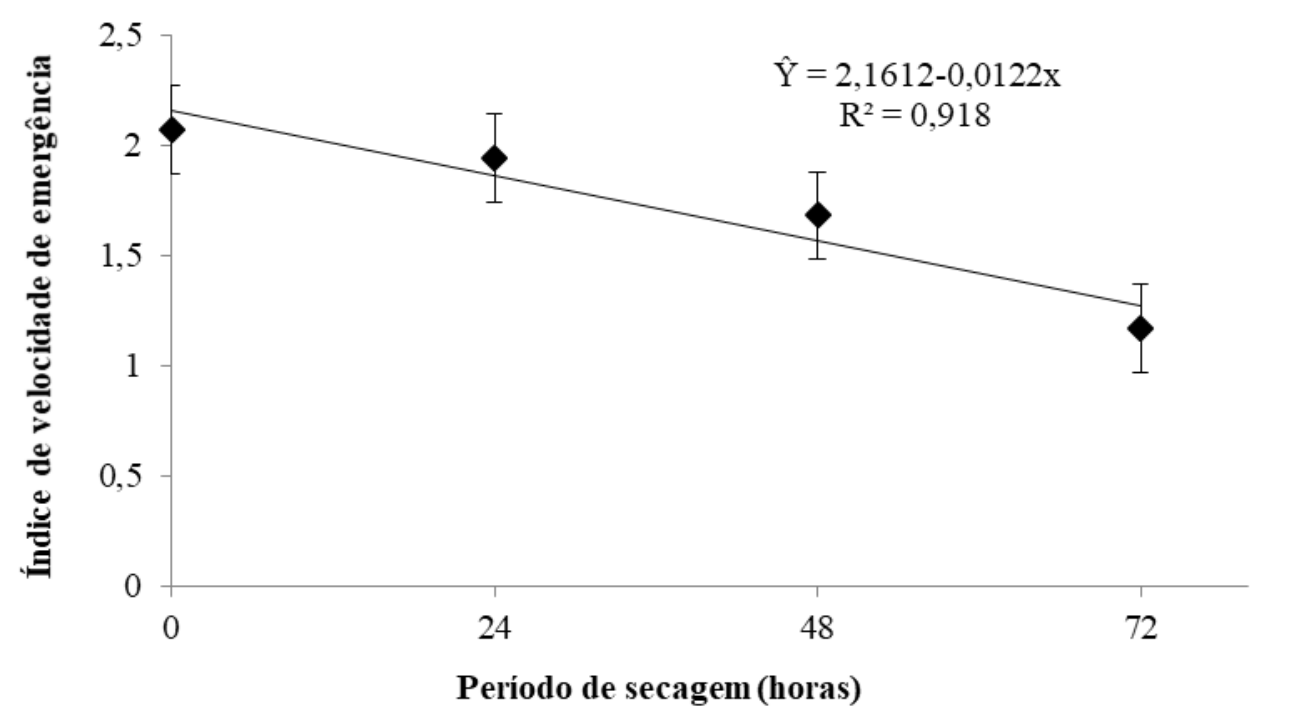

Figura 5. Índice de velocidade de emergência de plântulas oriundas de sementes de cacau submetidas a diferentes períodos de secagem. Index of emergence speed of seedlings from cocoa beans submitted to different drying periods.

Para o comprimento de plântulas (cm) (Figura 6) a tendência dos resultados foi similar à verificada para os demais testes de germinação e vigor, evidenciando o efeito negativo da secagem sobre a qualidade fisiológica das sementes, o que confirma o comportamento recalcitrante das sementes de cacau.

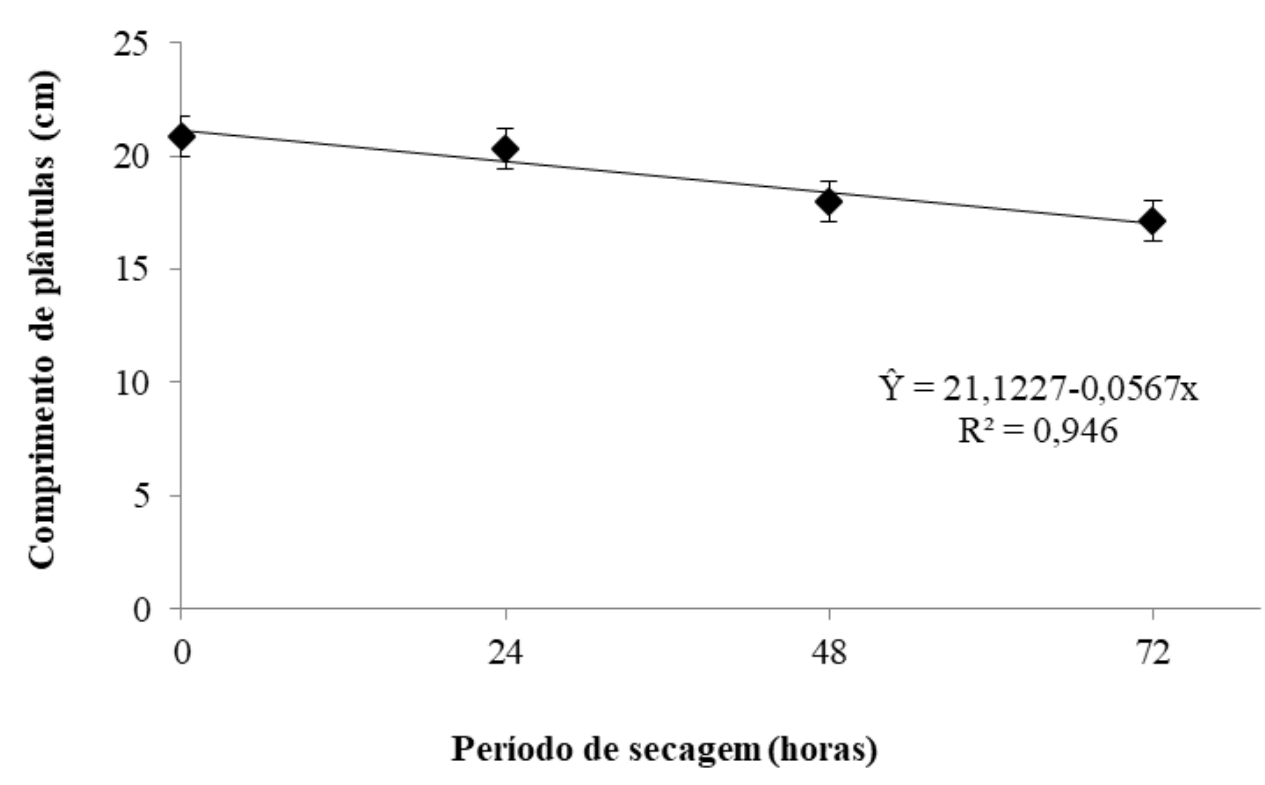

Figura 6. Comprimento de plântulas $(\mathrm{cm})$ oriundas de sementes de cacau submetidas a diferentes períodos de secagem. Length of seedlings from cocoa beans submitted to different drying periods.

O maior comprimento de plântulas $(20,89 \mathrm{~cm})$ foi obtido de sementes que foram avaliadas imediatamente após a sua extração (0h). A partir do maior comprimento, houve reduções nos valores, sendo verificado comprimento de $3,76 \mathrm{~cm}$ até o último período de 
secagem das sementes (Figura 6).

Neves et al. (1994) constataram em estudos que o tempo de viabilidade de sementes recalcitrantes em função de perda de água e mudanças de temperatura durante a germinação resulta em perda de vigor, devido a alterações da estrutura das membranas celulares do hipocótilo. Nascimento et al. (2007) também constataram que a desidratação crescente afetou o vigor das sementes de Euterpe oleracea Mart, causando redução do comprimento das plântulas.

Devido às características de formação das sementes de cacau, faz-se necessário observar a viabilidade das sementes utilizadas como propágulos, pois a perda de viabilidade é um comportamento genético, embora sejam relatadas como recalcitrantes, é possível identificar genótipos mais tolerantes à dessecação do embrião (VENIAL et al., 2017), o que viabiliza a qualidade fisiológica das sementes em processos de secagem.

Contudo, diante das variáveis analisadas nesta pesquisa, nota-se que a secagem afetou a germinação e o vigor das sementes de cacau CEPEC 2002, o que confirma sua sensibilidade à dessecação, com efeitos fisiológicos prejudiciais, em especial, em períodos prolongados de secagem.

\section{CONCLUSÃO}

As sementes de cacau apresentam comportamento recalcitrante, comprometendo a viabilidade e o vigor à medida que o seu teor de água é reduzido.

A secagem até o período de 24 horas mantém alta viabilidade das sementes.

\section{REFERÊNCIAS BIBLIOGRÁFICAS}

BERJAK, P.; PAMMENTER, N. W. Orthodox and recalcitrant seeds. In: VOZZO, J. A. Tropical tree seed manual. Washington: USDA Forest Science, 2003. cap. 4, p. 137-147.

BRASIL. Ministério da Agricultura, Pecuária e Abastecimento. Regras para análise de sementes. Brasília, DF: Secretaria de Defesa Agropecuária, 2009. 399p.

CARDOSO, E. C.; ALVES, E. U.; ALVES, A. U. Qualidade de sementes de pitombeira em função do período e da temperatura de secagem. Semina: Ciências Agrárias, Londrina, v. 36, n. 1, p.7-16, 2015.

CARVAlHO, L. R.; SILVA, E. A. A.; DAVIDE, A. C. Classificação de sementes florestais quanto ao comportamento no armazenamento. Revista Brasileira de Sementes, Londrina, v. 28, n. 2, p. 15-25, 2006. Disponível em: http://www.scielo.br/pdf/rbs/v28n2/a03v28n2.pdf. Acesso em: 20 jan. 2019.

CHIN, H. F.; KRISHNAPILLAY, B.; STANWOOD, P. C. Seed moisture: recalcitrant vs. orthodox seeds. In: STANWOOD, P. C.; McDONALD, M. B. Seed Moisture. CSSA: Special Publication, 1989. cap. 2, p. 15-22. Disponível em: http://www.worldcocoafoundation.org/wp-content/uploads/files_mf/chin1996.pdf. Acesso em: 24 jan. 2019. 
FIGUEIREDO, J. C.; DAVID, A. M. S. S.; SILVA, C. D.; AMARO, H. T. R.; ALVES, D. D. Maturação de sementes de pimenta em função de épocas de colheita dos frutos. Revista Scientia Agraria, v. 18, n. 3, p.01-07, 2017. Disponível em: https://revistas.ufpr.br/agraria/article/view/51324/33586. Acesso em: 01 ago. 2019.

LIMA, J. D.; ALMEIDA, C. C.; DANTAS, V. A. V.; SILVA, B. M. S.; MORAES, W. S. Efeito da temperatura e do substrato na germinação de sementes de Caesalpiniae ferrea Mart. ex Tul. (Leguminosae, Caesalpinioidae). Revista Árvore, Viçosa, MG, v. 30, n. 4, p.513-518, 2006. Disponível em: http://www.scielo.br/pdf/rarv/v30n4/31671.pdf. Acesso em: 20 jan. 2019.

MAGUIRE, J. D. Speed of germination: aid in selection and evaluation for seedling emergence and vigour. Crop Science, Madson, v. 2, n. 2, p.176-177, 1962.

NAKAGAWA, J. Testes de vigor baseados no crescimento de plântulas. In: VIEIRA, R.D.; CARVALHO, N.M. de. Testes de vigor em sementes. Jaboticabal: FUNEP, 1994. 164p.

NASCIMENTO, W. M. O; NOVEMBRE, A. C; CICERO, S. M. Consequências Fisiológicas da Dessecação em Sementes de Açaí (Euterpe oleracea Mart.). Revista Brasileira de Sementes, Londrina, v. 29, n. 2, p.38-43, 2007. Disponível em: http://www.scielo.br/pdf/rbs/v29n2/v29n2a06.pdf. Acesso em: 20 jan. 2019.

NAUTIYAL, A. R.; PUROHIT, A. N. Seed viability in sal. II. Physiological and biochemical aspects of ageing in seeds of Shorea robusta. Seed Science and Technology, Zurich, v. 13, n. 1, p.69-76, 1985.

NAZÁRIO, P.; FERREIRA, S. A. N; REBOUÇAS, E. R. Germinação de sementes de Cynometra bauhiniifolia Benthan (jutairana) em função do dessecamento e da manutenção sob condição úmida. Acta Amazônica, Manaus, v. 38, n. 3, p.439-444, 2008.

NEVES, C. S. V. J. Sementes recalcitrantes- Revisão de Literatura. Pesquisa Agropecuária Brasileira, Brasília, DF, v. 29, n. 9, p. 1459-1467, 1994.

OBROUCHEVA, N.; SINKEVICH, I.; LITYAGINA, S. Physiological aspects of seed recalcitrance: a case study on the tree Aesculus hippocastanum. Tree Physiology, Oxford, v. 36, p.1127-1150, 2016. Disponível em: https://academic.oup.com/treephys/article/36/9/1127/2465896. Acesso em: 20 jan. 2019.

OLIVEIRA, L. M.; SILVA, E. O.; BRUNO, R. L. A.; ALVES, E. U. Períodos e ambientes de secagem na qualidade de sementes de Genipa americana L. Semina: Ciências Agrárias, Londrina, v. 32, n. 2, p.495-502, 2011.

PIROLA, K.; DOTTO, M.; CASSOL, D. A.; WAGNER JUNIOR, A.; POSSENTI, J. C.; CITADIN, I. Sensibilidade à dessecação em sementes de seis fruteiras nativas. Revista de la Facultad de Agronomía, La Plata, v. 117, n. 1, p.31-41, 2018. Disponível em: http://sedici.unlp.edu.ar/bitstream/handle/10915/70863/Documento_completo.pdfPDFA.pdf?sequence=1\&isAllowed=y. Acesso em: 28 jan. 2019.

SODRÉ, G.A. Formação de mudas de Cacaueiro, onde nasce a boa cacauicultura. Ilhéus: CEPLAC/CEPEC, 2013. 48 p. (Boletim Técnico, 202). Disponível em: 
http://www.ceplac.gov.br/paginas/publicacoes/paginas/boletim_tecnico/cartilhas/BOLETIM\% 20T\%C3\%89C.\%20N\%C2\%BA\%20202.pdf. Acesso em: 25 jan. 2019.

TOYYIB, M.; GUNAWAN, B.; HARIYADI, B. W. The effect of sawdust and chaff media storage on cocoa (Theobroma cacao L.) seeds viability. Agricultural Science, [S. l.], v. 1, n. 1, p.37-46, 2017. Disponível em: http://agriscience.scientificwork.org/index.php/agriscience/article/view/12/4. Acesso em: 28 jan. 2019.

VENIAL, L. R.; ALEXANDRE, R. S.; CAMATA, H.; LOPES, J. C.; ZANOTTI, R. F.; FERREIRA, A.; AGUILAR, M. A. G. Biometria e armazenamento de sementes de genótipos de cacaueiro. Pesquisa Florestal Brasileira, Brasília, DF, v. 37, n. 89, p.39-46, 2017. Disponível em: https://pfb.cnpf.embrapa.br/pfb/index.php/pfb/article/view/1239/555. Acesso em: 25 jan. 2019. 